\title{
Estudo sobre a implantação do orçamento baseado em desempenho na Autoridade Portuária de Valência
}

\author{
Rogério João Lunkes \\ Universidade Federal de Santa Catarina \\ Vicente Ripoll-Feliu \\ Universidad de Valencia \\ Arturo Giner-Fillol \\ Autoridad Portuaria de Valencia
}

Fabricia Silva da Rosa

Universidade de Blumenau

\begin{abstract}
O crescimento e o desenvolvimento da economia mundial têm dependido cada vez mais do transporte marítimo, e os portos são um elo importante nesse processo. O presente estudo tem como objetivo explorar a aplicação do orçamento baseado em desempenho no sistema de portos da Espanha. Para tanto, foi realizado um estudo sobre o modelo orçamentário do Sistema Portuário de Titularidade Estatal e um estudo de caso na Autoridade Portuária de Valência. Os resultados mostram que as mudanças no orçamento geraram maior integração entre as medidas de desempenho e as dotações orçamentárias, as quais são feitas com detalhamento do processo no nível operacional, o que inclui os projetos de investimento. Em nível de controle, o modelo permitiu melhorar a avaliação dos resultados por incluir outras medidas de desempenho, além de receitas e custos, que podem ser comparados com outros portos do país e do exterior.
\end{abstract}

Palavras-chave: orçamento; orçamento de investimento; desempenho; porto.

Estudio sobre la ejecución del presupuesto basado en el desempeño de la Autoridad Portuaria de Valencia

El crecimiento y desarrollo de la economía mundial depende cada vez más del transporte Marítimo, siendo los puertos un eslabón importante en este proceso. El objetivo del presente estudio es explorar la aplicación del presupuesto basado en el desempeño en los puertos españoles. Para alcanzarlo, se llevo a cabo un estudio sobre el modelo presupuestario del Sistema Portuario de Titularidad Estatal analizándose además el caso de la Autoridad Portuaria de Valencia. Los resultados muestran que los cambios en el presupuesto llevan a una mayor integración entre las medidas de desempeño y las asig-

Artigo recebido em 14 set. 2011 e aceito em 2 out. 2012.

Rev. Adm. Pública - Rio de Janeiro 47(1):49-76, jan./fev. 2013 
naciones presupuestarias, que se hacen con los detalles del proceso en el nivel operativo, que incluye también lo proyectos de inversión. En el nivel de control, el modelo ha mejorado la evaluación de los resultados mediante la inclusión de otras medidas de rendimiento y los ingresos y gastos, que se pueden comparar con otros puertos a nivel nacional e internacional.

Palabras clave: presupuesto; presupuesto de inversión; desempeño; puerto.

Performance-Based Budgeting study of the implementation in Valenciaport

The growth and development of world economy has increasingly depended in shipping and ports are an important link in this process. This study aims to explore the application of performance-based budgeting system in the ports of Spain. To this end, we performed a study on the budget model of the Port System and State Ownership of a case study in the Port of Valencia. The results show that changes in the budget generated a greater integration of performance measures with budget appropriations, detailing the process at the operational level, which includes investment projects. The level of control allows the model to improve the evaluation of the results by including other measures of performance as well as revenues and costs, which can be compared with other ports in the country and abroad.

KEY WORDS: budgeting; investment budgeting; performance; port.

\section{Introdução}

Os estudos empíricos demonstram que o orçamento continua sendo um dos instrumentos mais importantes no planejamento e controle e amplamente utilizado pelas organizações (AbdelKader e Luther, 2006; Uyar, 2009; Sivabalan et al., 2009; Libby e Lindsay, 2010; Ostergren e Stensaker, 2011; Uyar e Bilgin, 2011).

Horngren, Foster e Datar (2000) definem o orçamento como a expressão quantitativa do plano de ação, proposto pela administração por um período determinado, que auxilia a coordenar o que precisa ser feito para implementar esse plano. Blumentritt (2006) postula que o orçamento é o processo de alocação de recursos financeiros de uma organização, de suas unidades, atividades e investimentos. Assim, as organizações utilizam o orçamento para diferentes fins e razões.

Essas diferentes formas de utilizar o processo orçamentário têm levado há um intenso debate. Se, de um lado, há uma corrente que defende que o orçamento deva ser eliminado das organizações (Leahy, 2002; Neely, Bourne e Adams, 2003; De Waal, 2005; Player, 2003; Hope e Fraser, 1999, 2003; Ripoll e Requena, 2005; Mcvay e Cooke, 2006; Rickards, 2006; Bishop, 2004; Libby e Lindsay, 2007; Uyar, 2009); por outro, os estudos sobre as formas de melhorar o processo orçamentário, como o orçamento-programa, têm crescido, principalmente os vinculados a organizações públicas (Classen, 1971; Fairholm e Card, 2009; Ter Bogt e Van Helden, 2011), bem como aquelas pesquisas sobre a integração entre medidas de desempenho (objetivos e metas do planejamento estratégico) com as dotações orçamentárias (Cope, 1987; Grizzle, 1986, 1987; Poister e Mcgowan, 1984; Poister e Streib, 1989, 1999, 2005; Schick, 1990; Berman e Wang, 2000; Melkers e Willoughby, 2005; Hatry, 2006; Ho, 
2011), além de estudos sobre a utilização de práticas de orçamento (Schmidgall e Ninemeier, 1986, 1987; Umapathy, 1987; Schmidgall, Borchgrevink e Zahl-Begnum, 1996; Schmidgall e DeFranco, 1998; Jones, 1998, 2008a, 2008b; Subramaniam, Mcmanus e Mia, 2002; Winata e Mia, 2005; Prendergast, West e Shi, 2006; Yuen, 2006; Rankin, Schwartz e Young, 2008; Pavlatos e Paggios, 2009; Oak e Schmidgall, 2009; Derfuss, 2009; Steed e Gu, 2009; King, Clarkson e Wallace, 2010; Uyar e Bilgin, 2011; Castro et al., 2012).

Os estudos sobre as práticas orçamentárias demonstram, em geral, que as organizações usam apenas parcialmente muitas das técnicas, além de não integrarem as medidas de desempenho com as dotações e de não criarem sistemas de incentivo e motivação para que os objetivos do orçamento sejam atingidos. Para Ho (2011), apesar das inovações da literatura, as informações de desempenho raramente são usadas em decisões sobre dotações orçamentárias, o que acaba gerando falhas no sistema de gestão das organizações. Além disso, muitas das soluções apresentadas na literatura resolvem apenas parte da questão relacionada à eficácia organizacional, além de lidarem somente com alguns dos dilemas organizacionais (Ter Bogt e Van Helden, 2011).

De uma forma geral, governos de diferentes partes do mundo estão realizando mudanças no processo orçamentário, visando melhorar a eficiência, a eficácia, a economia e o desempenho deste. Isso tem ocorrido em instituições públicas da Turquia (Tuegen et al., 2008), em governos locais da África do Sul (Graves e Dollery, 2009), no governo do Barém (Ramadham, 2009), numa província da Holanda (Ter Bogt e Van Helden, 2011) e numa da Espanha (Prieto, Zofio e Alvarez, 2009), e em uma universidade Australiana (Moll e Hoque, 2011).

Um ponto comum nesses debates diz respeito à necessidade de melhorar o processo orçamentário, visando obter mais benefícios (Uyar e Bilgin, 2011). No caso específico dos portos espanhóis, o orçamento não apresentava formatação prévia, sendo elaborado com base no ano anterior. Isso dificultava a consolidação do setor portuário, pois as análises eram centradas no ano, e o enfoque era baseado em critério de controle preventivo sobre os gastos.

Visando mudar essa realidade, em 2004, o Sistema Portuário de Titularidade Estatal (SPTE) espanhol criou um grupo de estudos a fim de melhorar a aplicação do processo orçamentário. Com a finalidade de pesquisar essa mudança, o presente estudo tem por objetivo explorar a aplicação do orçamento baseado em desempenho no sistema portuário espanhol e um estudo de sua aplicação na Autoridade Portuária de Valência.

Embora o orçamento seja um dos temas mais estudados pela academia devido a sua importância prática, na opinião dos autores, ele precisa ser pesquisado de forma mais ampla, especialmente no setor público. Como o tema é amplo e permite várias formas e tomar diferentes direções, o foco do estudo está mais centrado nos aspectos da integração das medidas de desempenho com as dotações orçamentárias, bem como descrever as novas práticas de orçamento implementadas no porto. Assim, este estudo visa contribuir para a literatura existente sobre orçamento em organizações públicas.

A pesquisa se justifica por várias razões. Primeiramente ela trará uma contribuição para a literatura, já que na revisão se constatou a falta de estudos sobre o tema aplicado a portos. Aliado a isso, ela pode ser utilizada como referência nos portos brasileiros, para melhoria 
do sistema de gestão, uma vez que o modelo portuário de administração utilizado no Brasil é semelhante, na sua estruturação (de caráter público), ao utilizado na Espanha. O aperfeiçoamento da gestão dos portos nacionais terá um impacto direto sobre a sociedade, pois os ganhos de competitividade terão reflexos nos demais setores econômicos e, principalmente, na zona de influência do porto.

No Brasil, 90\% dos produtos importados ou exportados passam pelos portos públicos ou pelos terminais de uso privativo (Agência Nacional de Transportes Aquaviários, 2010). Os portos brasileiros precisam remodelar seus sistemas gerenciais e isso inclui o desenvolvimento de novos sistemas de gestão (Brooks, 2004). Essa nova realidade dará lugar a uma maior responsabilidade dos portos em ações estratégicas e à necessidade de planejamento na determinação dos serviços integrados oferecidos e na projeção das necessidades de infraestruturas básicas (Herver, Mesersman e Van Der Voorde, 2001).

Este estudo está estruturado em cinco seções, contando com esta primeira, de introdução. A segunda seção apresenta o referencial teórico. A terceira consiste na exposição dos procedimentos metodológicos utilizados pela pesquisa. Na quarta seção, apresentam-se os resultados da pesquisa e, na quinta, são feitas as considerações finais.

\section{Revisão de literatura: orçamento}

O orçamento pode ser definido como: (i) um plano administrativo (Welsch, 1973; Kenski, 1973; Zdanowicz, 1989; Tung, 1994; Sanvicente e Santos, 2000; Horngren, Foster e Datar, 2000; Lunkes, 2007; Bencini et al., 2009; Muñiz, 2009; Álvares-Dardet Espejo e Gutiérez Hidalgo, 2010; Lunkes, Ripoll e Rosa, 2011); (ii) um guia para as operações (Lunkes, 2007); (iii) um plano abrangendo todas as fases das operações; (iv) um plano orientado pelos objetivos e metas (Zdanowicz, 1989); (v) para um período futuro definido (Welsch, 1973; Kenski, 1973; Zdanowicz, 1989; Tung, 1994; Horngren, Foster e Datar, 2000; Lunkes, 2007; Bencini et al., 2009; Muñiz, 2009; Álvares-Dardet Espejo e Gutiérez Hidalgo, 2010).

O orçamento pode fazer parte de um processo maior, que inicia com o desenvolvimento do planejamento estratégico da organização e é finalizado com a definição das atividades necessárias a sua operacionalização, o que gera um plano de metas e recursos que orienta a execução e pode então ser comparado com o realizado, visando analisar os desvios e implementar as medidas de adequação.

Estudos sobre a integração das medidas de desempenho com as dotações orçamentárias tornaram-se frequentes desde a década de 1980 (Poister e Mcgowan, 1984; Cope, 1987; Grizzle, 1986, 1987; Schick, 1990; Poister e Streib, 1989, 1999, 2005; Berman e Wang, 2000; Melkers e Willoughby, 2005; Hatry, 2006; Ho, 2011). Nessa concepção, as dotações orçamentárias são estabelecidas exclusivamente com base no desempenho (Ho, 2011).

Os processos de planejamento e controle se equiparam a um sistema que permeia todos os níveis de gestão, integrando aspectos funcionais e operacionais. As medidas devem ser atribuídas aos responsáveis por sua execução, devendo incluir as etapas de controle. Na gestão 
pública, a maior utilização da medição de desempenho é para fins gerenciais, por exemplo, para auxiliar na integração com o planejamento estratégico, na avaliação de programas e de melhoria, na avaliação de pessoal e de comunicação interna (Poister e Streib, 1999; Melkers e Willoughby, 2005; Ho, 2011).

Aliada à discussão sobre a integração do orçamento com as medidas de desempenho do planejamento estratégico está a utilização plena dos mecanismos ou práticas orçamentárias. A literatura nacional e a internacional apontam distintas características para o processo orçamentário (Schmidgall e Ninemeier, 1986, 1987; Umapathy, 1987; Schmidgall, Borchgrevink e Zahl-Begnum, 1996; Schmidgall e DeFranco, 1998; Jones, 1998, 2008a, 2008b; Subramaniam, Mcmanus e Mia, 2002; Winata e Mia, 2005; Prendergast, West e Shi, 2006; Yuen, 2006; Rankin, Schwartz e Young, 2008; Pavlatos e Paggios, 2009; Oak e Schmidgall, 2009; Derfuss, 2009; Steed e Gu, 2009; King, Clarkson e Wallace, 2010; Uyar e Bilgin, 2011; Castro et al., 2012). Essas principais características do processo orçamentário apontadas na literatura estão ilustradas no quadro 1.

\section{Principais características no orçamento}

\begin{tabular}{|ll|}
\hline Manual de orçamento & $\begin{array}{l}\text { Inclui diretrizes, objetivos, metas e indicadores previamente definidos } \\
\text { pela alta administração. }\end{array}$ \\
\hline Comitê de orçamento & $\begin{array}{l}\text { Pode incluir proprietários, diretores e gerentes gerais, chefes de } \\
\text { departamentos, controller etc. }\end{array}$ \\
\hline Formas de elaboração & $\begin{array}{l}\text { Top-down: o orçamento é elaborado pela alta administração e imposto } \\
\text { aos demais membros da organização. }\end{array}$ \\
& $\begin{array}{l}\text { Bottom-up: o orçamento é elaborado pelos centros ou } \\
\text { departamentos responsáveis e encaminhado à alta administração para } \\
\text { a aprovação. } \\
\text { Combinação: o orçamento é elaborado por meio de um processo } \\
\text { interativo entre centros responsáveis e alta administração. }\end{array}$ \\
\hline Período & Menos de um ano, um ano, plurianual. \\
\hline Revisão & Mensal, trimestral e semestral etc. \\
\hline Tipo de orçamento & Orçamento público \\
& Orçamento empresarial \\
& Orçamento de base zero \\
& Orçamento flexível \\
& Orçamento por atividades \\
& Beyond budgeting \\
\hline
\end{tabular}




\begin{tabular}{|c|c|}
\hline \multirow[t]{5}{*}{ Objetivos pretendidos } & Previsões de futuro \\
\hline & Maximizar resultados \\
\hline & Introduzir novos produtos e serviços \\
\hline & Planificar, controlar e valorar o resultado \\
\hline & Criar incentivos e recompensas \\
\hline \multirow[t]{7}{*}{ Finalidades } & Auxiliar no planejamento de longo prazo \\
\hline & Auxiliar no planejamento de curto prazo \\
\hline & Avaliar o desempenho \\
\hline & Coordenar as operações \\
\hline & Motivar os funcionários \\
\hline & Comunicar os planos \\
\hline & Controle \\
\hline \multirow[t]{5}{*}{ Informações utilizadas na elaboração } & Resultados dos anos anteriores \\
\hline & Estatística \\
\hline & Análise de mercado \\
\hline & Indicadores econômicos nacionais \\
\hline & Indicadores econômicos locais e regionais \\
\hline \multirow[t]{6}{*}{ Critérios utilizados para avaliar os resultados } & Benchmarking \\
\hline & Não usam pontos de referência \\
\hline & Usam pontos de referência \\
\hline & Valor monetário \\
\hline & Percentual \\
\hline & Repetição de uma variável adversa \\
\hline \multirow[t]{3}{*}{ Papel no monitoramento } & Principal indicador de desempenho \\
\hline & Um dos poucos indicadores-chave utilizados \\
\hline & Pouco utilizado como medida de desempenho \\
\hline \multirow[t]{5}{*}{ Responsáveis pelas variações } & Chefes de departamentos \\
\hline & Alta administração \\
\hline & Comitê de orçamento \\
\hline & Gerente geral \\
\hline & Centro de responsabilidade \\
\hline \multirow[t]{5}{*}{ Finalidade de análise das variações } & Avaliar o desempenho do gestor \\
\hline & Avaliar a capacidade de previsão do responsável \\
\hline & Controlar gastos \\
\hline & Reconhecimento a tempo de um problema \\
\hline & Feedback para o orçamento do próximo período \\
\hline
\end{tabular}

Fonte: Elaborado pelos autores. 
Além dessas características apresentadas no quadro 1, outras podem ser destacadas, como o tempo necessário à elaboração e preparação, o período dos relatórios, os programas ou softwares utilizados e se o orçamento enfatiza a estratégia ou o controle.

Horngren, Foster e Datar (2000) destacam, como características gerais de organizações adequadamente gerenciadas quanto ao aspecto orçamentário, os seguintes pontos: (i) o desempenho da organização é planejado em sua totalidade, sendo aplicado também nas subunidades; (ii) são fixados parâmetros de referência na forma de conjuntos de expectativas a serem comparados com os resultados reais alcançados; (iii) faz-se constante avaliação dos rumos das estratégias, com abertura para ações corretivas, se necessárias; e (iv) caso seja constatado um feedback discrepante do planejado, faz-se o replanejamento das ações por meio das medidas corretivas.

Estudos realizados por Umapathy (1987) e King, Clarkson e Wallace (2010) mostram que as empresas de sucesso, de fato, adotavam algumas práticas que tornavam seus sistemas orçamentários mais eficazes. Entre as práticas destacadas estão: geração de compromisso, alinhamento entre os níveis da organização, adoção de procedimentos detalhados e abrangentes na elaboração, análise das variações e tomada de ações corretivas.

Os objetivos do orçamento devem estar alinhados com os definidos no planejamento nos níveis estratégico e tático. Além disso, devem estar relacionados ao ciclo administrativo: planejamento, execução e controle. No planejamento, o orçamento pode materializar os objetivos sob a forma de valor. Na execução, o orçamento contribui para orientar as ações e decisões, visando assegurar a eficácia da organização e o comando que vai possibilitar a difusão dos planos. Isso serve para coordenar os diversos centros de responsabilidade da organização, motivando e avaliando os colaboradores.

O orçamento pode também contribuir para a avaliação de desempenho, sendo suas medidas comparadas com o realizado. Assim, ele fornece as medidas para avaliar o resultado global da organização e o desempenho dos diferentes centros de responsabilidade, por meio de análise e identificação dos desvios, e, em caso de necessidade, da elaboração das medidas de adequação. Pode, ainda, ser aplicado de diferentes formas; entre os processos, podem-se destacar: orçamento empresarial, contínuo, de base zero, flexível, por atividades, além do beyond budgeting (Lunkes, 2007).

\section{Metodologia}

Nesta seção apresentam-se os procedimentos metodológicos utilizados para a construção do referencial teórico e os procedimentos para o estudo prático.

\subsection{Construção do referencial teórico}

O processo para seleção e análise de referências bibliográficas está dividido em três fases: escolha das bases de dados, seleção de artigos e análise sistêmica (Rosa, Ensslin e Ensslin, 
2009). A primeira fase fundamenta a escolha da base de dados; a segunda obtém um portfólio de artigos; e a terceira apresenta a análise bibliométrica e sistêmica do portfólio de artigos.

As delimitações utilizadas no processo foram: (i) bases de dados: Scopus e ISI; e (ii) palavras-chave: budgeting; management; performance; economic; business. Com base nessa estrutura, foram selecionados 269 artigos alinhados com o tema práticas de orçamento e 48 sobre desempenho orçamentário, os quais deram suporte à análise sistêmica apresentada no referencial teórico.

\subsection{Procedimentos para o estudo prático}

A partir da revisão da literatura, foram definidos critérios para realizar a descrição e a análise do modelo de orçamento desenvolvido para o sistema portuário espanhol. Para melhorar a compreensão do processo orçamentário, foi realizado um estudo na Autoridade Portuária de Valência (APV) analisando as mudanças ocorridas a partir do ano de 2004, para verificar vantagens, desvantagens e oportunidades de aperfeiçoamento.

Nesse processo de análise, verificou-se inicialmente que a mudança orçamentária da APV ocorreu no ano de 2004. Assim, com o intuito de analisar essa mudança, observou-se o processo de elaboração, revisão e acompanhamento do orçamento utilizado pela APV antes e depois de 2004. Para a coleta de dados sobre o processo orçamentário utilizado até o ano de 2004, fez-se um questionário semiestruturado, composto de 17 questões fechadas e abertas, e, para a análise do processo orçamentário posterior ao ano de 2004, foram coletados dados dos instrumentos financeiros e peças orçamentárias da APV no período de 2010-11, com participação direta dos pesquisadores.

Após a coleta de dados, foram feitas análises para: (i) identificar o diagnóstico da situação antes de 2004, (ii) verificar as oportunidades de melhorias desse processo orçamentário a partir da análise de critérios identificados na literatura, e (iii) analisar as melhorias que efetivamente ocorreram a partir da implementação do atual processo orçamentário da APV.

Entre o conjunto de critérios analisados na literatura, foram selecionados sete (apontados como os mais relevantes da literatura segundo a revisão realizada), conforme quadro 2.

\section{Quadro 2}

Diagnóstico da situação e oportunidades de melhoria do orçamento da APV

\begin{tabular}{|ll|}
\hline \multicolumn{1}{|c|}{ Critérios analisados } & \multicolumn{1}{c|}{ Oportunidades de melhoria encontradas na literatura } \\
\hline Manual de orçamento & $\begin{array}{l}\text { Inclui diretrizes, objetivos, metas e indicadores previamente definidos pela alta } \\
\text { administração. }\end{array}$ \\
Forma de elaboração & Top-down, bottom-up ou combinações de ambos os métodos. \\
Período de elaboração & Apresentar planejamento também para curto e longo prazo. \\
\hline
\end{tabular}




\begin{tabular}{|ll|}
\hline \multicolumn{1}{|c|}{ Critérios analisados } & \multicolumn{1}{c|}{ Oportunidades de melhoria encontradas na literatura } \\
\hline Objetivos do orçamento & $\begin{array}{l}\text { Previsões de futuro; maximizar resultados; introduzir novos produtos e serviços; planificar, } \\
\text { controlar e valorar o resultado; criar incentivos e recompensas. }\end{array}$ \\
Informações utilizadas & $\begin{array}{l}\text { Resultados dos anos anteriores; estatística; análise de mercado; indicadores econômicos } \\
\text { nacionais; indicadores econômicos locais e regionais. }\end{array}$ \\
Critérios de avaliação & $\begin{array}{l}\text { Benchmarking; não usam pontos de referência; usam pontos de referência; valor } \\
\text { monetário percentual; repetição de uma variável adversa. }\end{array}$ \\
Finalidade da análise das & $\begin{array}{l}\text { Avaliar o desempenho do gestor; avaliar a capacidade de previsão do responsável; } \\
\text { variações }\end{array}$ \\
& controlar gastos; reconhecimento a tempo de um problema; feedback para o orçamento \\
& do próximo período.
\end{tabular}

Fonte: Elaborado pelos autores.

Os aspectos relacionados no quadro 2 embasam a análise das mudanças no processo orçamentário na APV.

\section{Apresentação dos resultados}

Para entender melhor o desenvolvimento do modelo orçamentário, apresenta-se, na sequência, o sistema espanhol de portos.

\subsection{Sistema espanhol de portos}

Quando se faz referência ao sistema portuário espanhol, é fundamental realizar uma distinção entre os portos de interesse geral e os portos de refúgio, desportivos e, em geral, todos os que não desenvolvem atividades comerciais. A Administração Central do Estado, através do Ministério de Fomento, é quem tem a competência exclusiva sobre os portos de interesse geral. Os demais portos são administrados pelas Comunidades Autônomas, o que equivale aos estados brasileiros.

Os portos de interesse geral são aqueles que se enquadram em algumas das seguintes circunstâncias:

a) realizam atividades comerciais marítimas internacionais (portos comerciais);

b) sua zona de influência comercial afeta, de forma relevante, mais de uma Comunidade Autônoma;

c) prestam serviços a indústrias ou estabelecimentos de importância estratégica para a economia nacional;

d) o volume anual e as características de suas atividades comerciais marítimas alcançam níveis suficientemente relevantes ou respondem a necessidades essenciais da atividade econômica geral do Estado; 
e) suas especiais condições técnicas ou geográficas constituem elementos essenciais para a seguridade do tráfico marítimo, especialmente em territórios formados por ilhas.

O Ministério de Fomento, mediante o Organismo Público Puertos del Estado (OPPE), realiza a coordenação e o controle da eficiência do SPTE, sendo os portos de interesse geral gerenciados pelas autoridades portuárias (AAPP) em um regime de autonomia de gestão. A figura 1 apresenta graficamente o SPTE espanhol.

Figura 1

Descrição do SPTE

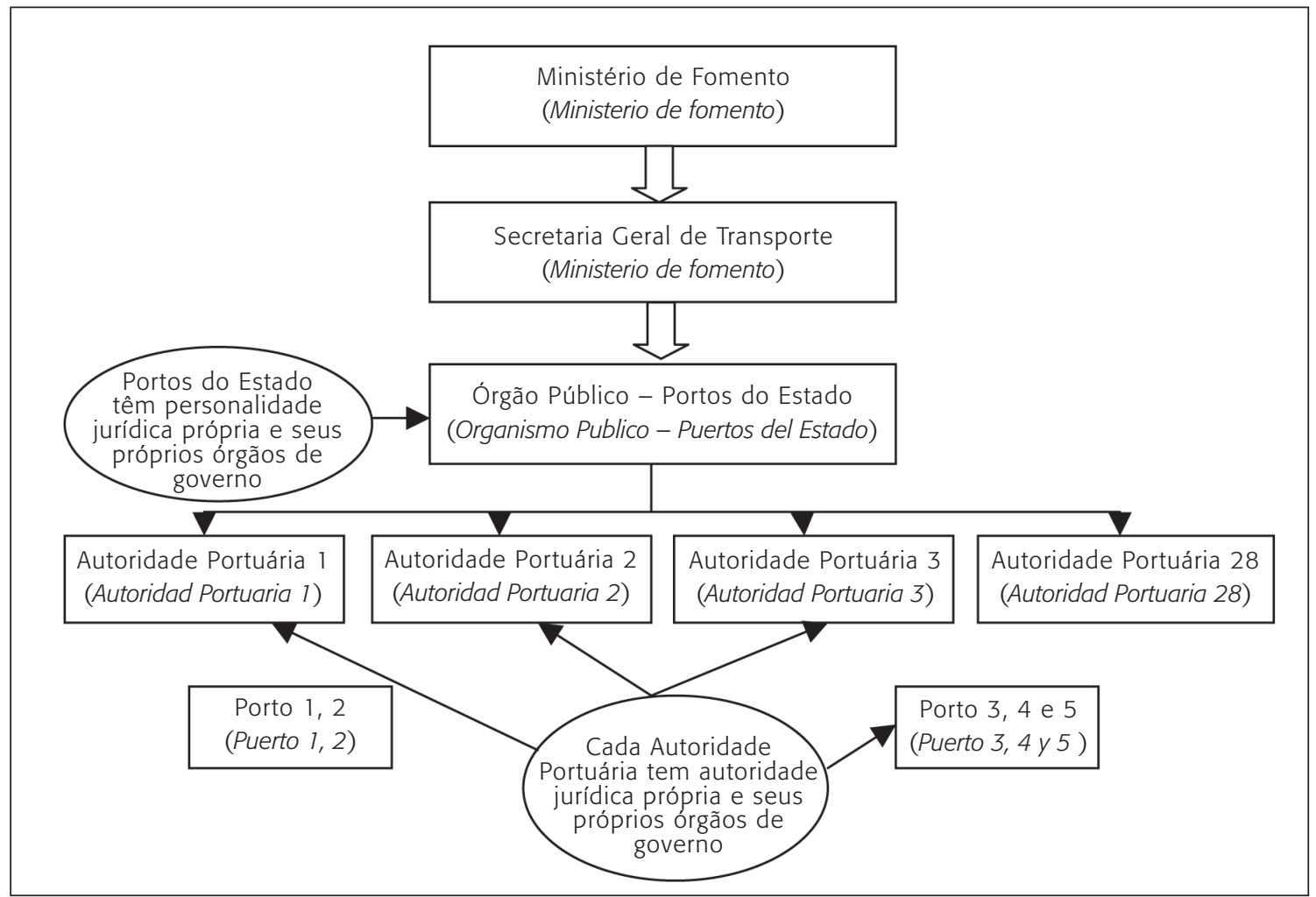

Fonte: Organismo Público Puertos del Estado (2011).

Assim, na Espanha, existem 28 AAPP que gerenciam 46 portos de interesse geral, dispondo, cada uma delas, de sua própria personalidade jurídica e órgãos de gestão e administração.

O modelo de gestão implantado na Espanha converte cada Autoridade Portuária (AP) na máxima responsável pela qualidade e eficiência dos serviços portuários prestados no interior de suas instalações; consequentemente, os serviços portuários podem ser valorados de maneira integral por parte de seus clientes, não sendo possível segregar sua operação em 
partes. Não obstante, isso não impede que, no contexto da competência interportuária, sua atuação seja condicionada por diretrizes fixadas por um organismo público de âmbito superior, como o OPPE.

Para finalizar, cabe ressaltar que os objetivos e princípios do regime econômico do SPTE espanhol são: autonomia de gestão de cada AP, autofinanciamento, otimização da gestão econômica, solidariedade, competência, liberdade tarifária, melhoria da competitividade e incentivo à participação da iniciativa privada. Na sequência, visando conhecer suas características e particularidades, será apresentado o sistema orçamentário espanhol.

\subsection{Visão macro do sistema orçamentário portuário espanhol}

A partir de 2004, coincidindo com a entrada em vigor do novo marco legal do SPTE, se produz uma mudança no sistema de elaboração e acompanhamento do orçamento das AAPP responsáveis pela gestão dos portos. Os princípios da técnica e o procedimento orçamentário que até então prevaleceriam nas AAPP eram os mesmos aplicados ao setor público e foram substituídos por outro sistema, baseado em critérios empresariais, no qual o orçamento é elaborado como parte do planejamento econômico-financeiro e integra o planejamento global do SPTE com horizonte de tempo superior a um ano e clara vinculação com o marco estratégico definido.

As principais mudanças ocorridas estão relacionadas à possibilidade de agrupar todos os orçamentos das AAPP em um único documento, o horizonte de tempo passa a ser plurianual, e a análise da eficiência e eficácia passa a ser de acordo com os objetivos estratégicos.

As alterações do sistema orçamentário estão ligadas à modernização do planejamento estratégico e, com ele, os processos e instrumentos de planejamento econômico-financeiro de curto prazo.

O grande desafio da nova proposta era compatibilizar as exigências de um orçamento consolidado, visando atender as necessidades de informação do setor público, com as demandas e desafios inovadores das atividades operacionais do porto.

\subsubsection{Procedimento orçamentário}

Como passo prévio à elaboração de um orçamento consolidado, cada Autoridade Portuária prepara um desenho de seu orçamento individual, orientado ao desenvolvimento das políticas e estratégias particulares próprias de seu âmbito de competência, mas em perfeito alinhamento com os objetivos e políticas gerais do conjunto do sistema portuário.

O orçamento individual, cujo compromisso de execução, controle e acompanhamento se estabelece em reuniões de planos de empresas (orçamento mais planos de objetivos) com o Organismo Público dos Portos do Estado (OPPE), configura-se como uma ferramenta que facilita a gestão econômico-financeira das AAPP, dando suporte à implantação dos seus objetivos. 
As características desse orçamento individual podem ser resumidas da seguinte forma:

a) é elaborado pela AP, mas de acordo com a OPPE, através do plano de empresas;

b) é um plano integrado de todas as unidades de negócio e do conjunto de portos gerenciados pela AP;

c) um dos fatores-chave do orçamento são os investimentos e seu financiamento;

d) engloba os estados econômico-financeiros das contas de resultado (lucros ou prejuízos), o quadro de financiamento e o balanço patrimonial. Para sua elaboração, é necessário prever o tráfico para o período orçado (vendas e receitas), os custos operacionais, os investimentos previstos (Plano Diretor de Infraestrutura) e o financiamento necessário;

e) seu horizonte temporal de informação contempla cinco anos;

f) deve existir uma clara vinculação com os objetivos e metas da AP, e com o horizonte de tempo definido.

O orçamento, uma vez elaborado, forma parte do Plano da AP, em que se estabelece o marco de atuação econômico e de gestão para os próximos cinco anos (as previsões do ano de elaboração orçamentário (ano $n+1)$ e a dos três exercícios seguintes $(n+2, n+3, n+4)$ ), e em que se incluem: (i) um diagnóstico da situação; (ii) as previsões de tráfico portuário, assim como as informações econômico-financeiras; (iii) o Mapa Estratégico, com objetivos e indicadores estratégicos; (iv) a estrutura de pessoal; (v) indicadores de gestão; (vi) análise das sociedades investidas; (vii) objetivos anuais de rentabilidade; (viii) descontos comerciais e outros cálculos para a aplicação das taxas portuárias; e (ix) plano de investimentos com objetivo de adequar a oferta de infraestruturas públicas às necessidades vinculadas ao tráfico portuário, acompanhado dos estudos de rentabilidade econômica ou da avaliação de seu impacto ambiental. O plano de investimentos de cada AP é analisado previamente pela comissão de investimentos formada com pessoal das distintas Diretorias da OPPE, cujo objetivo é avaliar a coerência dos investimentos que se realizam no sistema e aportar rigorosidade à avaliação dos projetos.

Com os orçamentos individuais elaborados e aprovados, consolida-se o orçamento global, formado pela integração das 28 AAPP e o da OPPE, totalizando 29 Organismos de Direito Público integrados em somente um orçamento, depois de realizar os ajustes de consolidação necessários.

Esse orçamento permite observar os valores globais do conjunto portuário e apreciar tanto a evolução, cujos valores são relacionados à consolidação de outros exercícios anteriores, como sua tendência futura. Pode-se analisar a situação econômico-financeira do SPTE, bem como realizar estudos de benchmarking comparativos com o setor portuário de outros países.

A Fase 1 de elaboração do orçamento da AAPP é realizada de acordo com formatos, instruções e objetivos desenvolvidos pelo OPPE, que são distribuídos anualmente. Com essas 
orientações e de acordo com o plano estratégico e diretor da própria AP, é elaborado o plano de investimentos, que deve ser enviado previamente à Comissão de Investimentos. O modelo de elaboração do sistema é apresentado na figura 2.

\section{Figura 2}

Visão geral do modelo orçamentário portuário espanhol

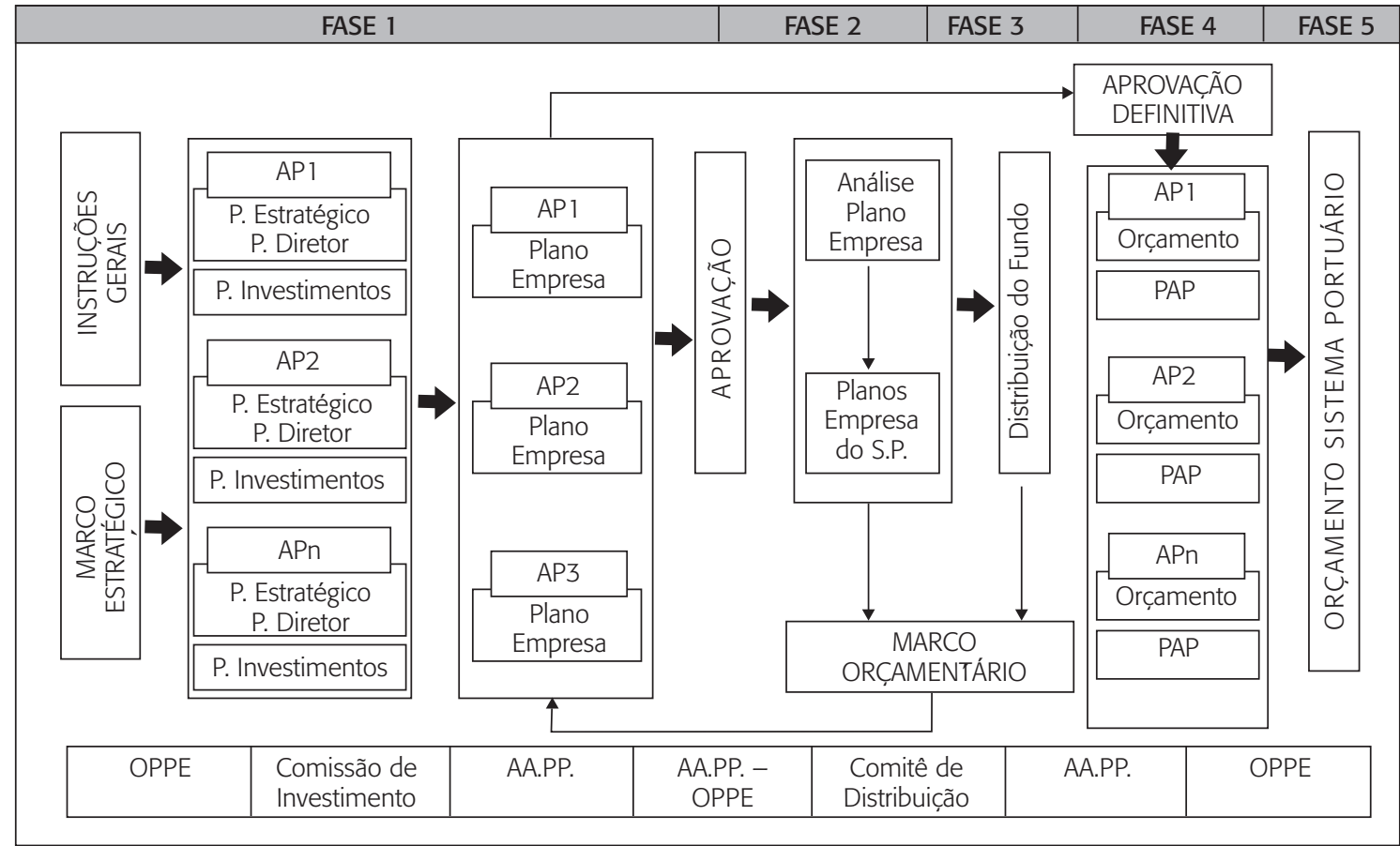

Fonte: Aeca (2006).

A partir dos resultados do plano de investimentos e do alinhamento dos objetivos e metas a cada centro de responsabilidade, inicia-se o orçamento dos diferentes departamentos, com a participação de todos os funcionários do porto, visando o comprometimento com as metas setoriais. As previsões de todos os departamentos formam o plano da empresa. Esse plano orçamentário passará por várias discussões e revisões para então ser aprovado pelo conselho diretor da AAPP e pelo OPPE.

Na segunda fase, os planos orçamentários dos diferentes portos são analisados e revisados e, a partir daí, são consolidados em um único orçamento. O Porto de Estado se encarrega de integrar o orçamento das AAPP e o seu próprio, além de elaborar o orçamento consolidado do SPTE. Na continuação, o orçamento é convertido em formato oficial, estabelecido pelo Ministério de Economia e Fazenda, para formar parte do Projeto do Orçamento, que será anexado ao Projeto de Lei do Orçamento e enviado ao Parlamento. 


\subsubsection{Modificações orçamentárias}

As AAPP, através de seu Conselho de Administração, têm a competência para realizar ajustes internos em seu orçamento, sem que isso envolva aumento dos gastos com pessoal ou aumento de investimentos. Quando as modificações implicam incrementos orçamentários operacionais ou de capital, elas devem submetê-los à decisão do OPPE, que, em função da natureza e importância, decidirá diretamente, através de seu Conselho Diretor, ou então submeterá sua decisão ao Ministério de Economia e Fazenda ou ao governo.

\subsection{Orçamento na Autoridade Portuária de Valência}

\subsubsection{Caracterização do porto}

A Autoridade Portuária de Valência (APV), cuja denominação comercial é Valenciaport, é uma empresa pública responsável pela gestão e administração de três portos de titularidade estatal, situados ao longo de 80 quilômetros do bordo oriental do Mediterrâneo espanhol: Sagunto, Valência e Gandia.

A Autoridade Portuária de Valência possui ligação direta com cinco rotas marítimas e ligação indireta com seis, apresentadas por González Laxe (2007), que possibilitam ligações com vários países dos cinco continentes.

Sua situação geográfica, privilegiada no centro do Arco Mediterrâneo Ocidental, em linha com o corredor marítimo leste-oeste que atravessa o Canal de Suez e o Estreito de Gibraltar, possibilita à Autoridade Portuária de Valência ser a primeira e última escala das principais companhias marítimas de linha regular entre a América, a Bacia do Mediterrâneo e o Extremo Oriente.

O Porto é o melhor e a mais eficiente opção de serviço de comércio marítimo do Sul da União Europeia. Possui mais de 140 linhas regulares, onde operam as principais companhias marítimas internacionais, que o conectam com mais de 850 portos dos cinco continentes.

Em relação ao acesso a centros de produção e distribuição, a APV abrange 51\% do PIB espanhol e compreende um hinterland em um raio de $350 \mathrm{~km}$, o que faz com que atenda à capital Madri e esteja interligada às principais cidades da Espanha, como Barcelona e Zaragoza. Além disso, permite distribuir, em um raio de $2 \mathrm{mil} \mathrm{km}$, a países do Sul da Europa e do Norte da África (Marrocos, Argélia, Tunísia e Líbia), com um mercado de 243 milhões de consumidores (Autoridad Portuaria de Valencia, 2011).

Paralelamente, dispõe de uma extensa rede de serviços feeder que a conecta com o Mediterrâneo Oriental e o mar Negro, o que impulsiona, em grande parte, o transbordo de contêineres. A APV é considerada a quinta melhor da Europa e a 25aㅡ do mundo em eficiência. 


\subsubsection{Processo orçamentário anterior}

O sistema de orçamento anterior era elaborado para atender aos preceitos do setor público espanhol (Lei Orçamentária), que envolve basicamente a projeção de receitas e gastos para um próximo ano. Assim, sua abrangência limitava-se a atender o PE (Puertos del Estado) com dados financeiros globais cujos níveis das operações não eram detalhados. A projeção dos dados era de responsabilidade da direção geral do porto. Para sua elaboração, utilizavam-se os resultados de anos anteriores e, em geral, aplicava-se um acréscimo em termos percentuais.

O controle era realizado comparando-se os dados dos projetos com os realizados, o que, pela falta de detalhamento, impossibilitava qualquer avaliação dos desvios e ações de melhoria ou atribuição de responsabilidade. O Porto também não tinha qualquer sistema de incentivos e motivação baseado nos resultados orçamentários.

O processo era essencialmente de responsabilidade da área econômica e financeira do Porto, isso inclui a elaboração e também o controle e acompanhamento dos orçamentos. Quanto às receitas, elas eram estimadas com base em projeções de receitas auferidas em anos anteriores, ajustadas pelas adições de novo tráfego e o final de concessões.

\subsubsection{Processo orçamentário atual}

Conforme apontado no item 4.2.1, o orçamento do porto deve conter, no mínimo, um diagnóstico da situação, as previsões de tráfego, previsões econômico-financeiras, objetivos de gestão, estrutura de pessoal e oferta de empregos, evolução dos indicadores de gestão, análise de sociedades participantes, programação financeira, programação de investimentos públicos, estimativa de investimentos privados, objetivo anual de rentabilidade, coeficiente de correção e cálculo dos descontos a serem aplicados às taxas portuárias no próximo exercício.

Na primeira fase, de acordo com a figura 2, a elaboração do orçamento ocorre a partir de instruções e orientações de caráter geral e de estratégica emitida anualmente pela EPPE. O formato em que deve ser elaborado o orçamento é desenvolvido pelos Portos do Estado e é distribuído com as instruções específicas. Ou seja, ele funciona como um manual de orçamento com diretrizes, parâmetros, metas e indicadores gerais para o porto.

O orçamento é elaborado para um período de cinco anos, ou seja, a partir da primeira elaboração desse período, no segundo ano é adicionado um novo ano, e são realizadas revisões nos demais períodos, o que inclui ajustes no ano vindouro.

Para iniciar o processo interno de elaboração dos orçamentos, os responsáveis pelos departamentos, em conjunto com os diretores do porto, estabelecem os principais objetivos que devem ser alcançados pelos centros. A literatura aponta que a participação dos empregados no processo orçamentário gera efeitos positivos sobre sua satisfação e motivação. Nessa direção, Yuen (2006) constatou que, em empresas na China, uma maior participação dos empregados aumenta-lhes a responsabilidade e as experiências. Os resultados dos estudos de 
Steed e Gu (2009) e de Uyar e Bilgin (2011), realizados em empresas nos Estados Unidos e na Turquia, corroboram os achados anteriores, ao apontarem que os bônus de desempenho estão diretamente ligados ao atingimento dos objetivos orçamentários. A remuneração variável, baseada nas metas orçamentárias, é uma alteração que foi introduzida a partir das modificações do modelo orçamentário.

Esse novo modelo de orçamentação se transforma em uma oportunidade para rever o negócio portuário. Receitas, custos, dados físicos e demais metas orçamentárias são projetados mediante estudos rigorosos sobre a evolução dos diferentes tráfegos do porto. A tabela 1 apresenta o orçamento de resultado, com as diferentes receitas e custos projetados pelo porto.

Tabela 1

Orçamento de resultado

\begin{tabular}{|c|c|c|c|c|c|c|c|}
\hline \multirow[b]{2}{*}{$\begin{array}{l}\text { Contas de resultado } \\
\text { (em milhares de reais) }\end{array}$} & \multicolumn{3}{|c|}{2011} & \multirow[b]{2}{*}{2012} & \multirow[b]{2}{*}{2013} & \multirow[b]{2}{*}{2014} & \multirow[b]{2}{*}{2015} \\
\hline & Realizado & $\begin{array}{l}\text { Orçamento } \\
\text { Aprovado }\end{array}$ & Previsão & & & & \\
\hline 1. Receitas & 107.337 & 114.659 & 117.659 & 127.404 & 137.800 & 150.187 & 157.435 \\
\hline A. Taxas Portuárias & 97.166 & 106.932 & 106.932 & 116.427 & 126.552 & 138.666 & 145.699 \\
\hline a) Taxa de ocupação & 23.232 & 24.096 & 24.096 & 26.640 & 29.429 & 34.647 & 36.250 \\
\hline b) Taxa de utilização & 61.489 & 70.131 & 70.131 & 75.346 & 81.256 & 86.958 & 91.547 \\
\hline 1. Taxa de navio & 22.705 & 27.207 & 27.207 & 29.043 & 31.318 & 33.556 & 35.904 \\
\hline $\begin{array}{l}\text { 2. Taxa de embarcações } \\
\text { desportivas e recreio }\end{array}$ & 545 & 745 & 745 & 760 & 775 & 791 & 807 \\
\hline 3. Taxa de passageiro & 1.100 & 954 & 954 & 1.214 & 1.425 & 1.560 & 1.681 \\
\hline 4. Taxa de mercadoria & 37.068 & 41.137 & 41.109 & 44.209 & 47.615 & 50.924 & 53.025 \\
\hline 5. Taxa de pesca fresca & 71 & 88 & 88 & 91 & 93 & 96 & 98 \\
\hline $\begin{array}{l}\text { 6. Taxa de utilização especial- } \\
\text { Zona trânsito }\end{array}$ & 0 & & 28 & 29 & 30 & 31 & 32 \\
\hline c) Taxa de atividade & 11.521 & 11.823 & 11.823 & 13.506 & 14.687 & 15.998 & 16.818 \\
\hline d) Taxa de ajuda à navegação & 924 & 882 & 882 & 935 & 1.000 & 1.063 & 1.084 \\
\hline B. Outras receitas de negócio & 10.171 & 7.727 & 10.727 & 10.977 & 11.248 & 11.521 & 11.736 \\
\hline a) Valores adicionais das taxas & 1.597 & 1.417 & 1.417 & 1.417 & 1.417 & 1.417 & 1.417 \\
\hline b) Tarifas e outros & 6.825 & 6.310 & 6.310 & 6.488 & 6.685 & 6.882 & 7.020 \\
\hline $\begin{array}{l}\text { c) Receitas geradas por direitos } \\
\text { de navios }\end{array}$ & 1.749 & & 3.000 & 3.072 & 3.146 & 3.222 & 3.299 \\
\hline $\begin{array}{l}\text { 3. Trabalhos realizados por empre- } \\
\text { sa - ativo }\end{array}$ & 184 & 40 & 40 & 40 & 40 & 40 & 40 \\
\hline 5. Outras receitas & 5.850 & 5.997 & 6.580 & 7.618 & 4.110 & 4.611 & 4.402 \\
\hline a) Receitas acessórias e correntes & 2.697 & 3.933 & 3.933 & 3.129 & 2.908 & 3.409 & 3.200 \\
\hline
\end{tabular}




\begin{tabular}{|c|c|c|c|c|c|c|c|}
\hline \multirow[b]{2}{*}{$\begin{array}{l}\text { Contas de resultado } \\
\text { (em milhares de reais) }\end{array}$} & \multicolumn{3}{|c|}{2011} & \multirow[b]{2}{*}{2012} & \multirow[b]{2}{*}{2013} & \multirow[b]{2}{*}{2014} & \multirow[b]{2}{*}{2015} \\
\hline & Realizado & $\begin{array}{c}\text { Orçamento } \\
\text { Aprovado }\end{array}$ & Previsão & & & & \\
\hline b) Subvenções & 84 & 70 & 70 & 70 & 70 & 70 & 70 \\
\hline $\begin{array}{l}\text { c) Receitas repassadas - } \\
\text { concessões revertidas }\end{array}$ & 1.126 & 1.132 & 1.132 & 1.132 & 1.132 & 1.132 & 1.132 \\
\hline $\begin{array}{l}\text { d) Fundo de compensação inter- } \\
\text { portuário }\end{array}$ & 1.943 & 862 & 1.445 & 3.287 & 0 & 0 & 0 \\
\hline 6. Gastos de pessoal & (19.878) & $(21.477)$ & $(21.477)$ & $(21.194)$ & $(20.890)$ & $(21.726)$ & $(22.378)$ \\
\hline a) Salários & $(14.085)$ & $(14.977)$ & $(14.977)$ & $(14.694)$ & $(14.390)$ & $(14.966)$ & $(15.415)$ \\
\hline b) Indenizações & (195) & 0 & 0 & 0 & 0 & 0 & 0 \\
\hline c) Encargos sociais & $(5.598)$ & $(6.500)$ & $(6.500)$ & $6.500)$ & $(6.500)$ & $(6.760)$ & (6.963) \\
\hline d) Provisões & 0 & 0 & 0 & 0 & 0 & 0 & 0 \\
\hline 7. Outros gastos & $(43.772)$ & $(34.721)$ & $(33.184)$ & $(32.526)$ & $(32.400)$ & (34.198) & $(35.402)$ \\
\hline A. Outros gastos & $(36.652)$ & $(26.660)$ & $(26.660)$ & $(25.261)$ & $(23.851)$ & $(24.848)$ & $(25.346)$ \\
\hline a) Serviços de terceiros & $(25.789)$ & $(21.312)$ & $(21.312)$ & $(20.062)$ & $(18.794)$ & $(19.760)$ & $(20.156)$ \\
\hline 1) Reparação e conservação & $(6.755)$ & $(6.214)$ & $(5.214)$ & $(4.953)$ & $(4.706)$ & $(4.753)$ & $(4.848)$ \\
\hline $\begin{array}{l}\text { 2) Serviços profissionais indepen- } \\
\text { dentes }\end{array}$ & $(6.070)$ & $(4.431)$ & $(4.431)$ & $(4.209)$ & $(4.000)$ & $(4.040)$ & $(4.121)$ \\
\hline 3) Matérias e consumos & (7.119) & $(5.634)$ & $(5.634)$ & $(5.352)$ & $(5.084)$ & $(5.135)$ & $(5.238)$ \\
\hline 4) Outros serviços de terceiros & $(5.845)$ & $(6.033)$ & $(6.033)$ & $(5.548)$ & $(5.004)$ & $(5.832)$ & $(5.949)$ \\
\hline b) Tributos & $(2.438)$ & $(2.355)$ & $(2.355)$ & $(2.355)$ & $(2.355)$ & (2.359) & $(2.406)$ \\
\hline c) Perdas, deterioração & $(5.210)$ & 0 & 0 & 0 & 0 & 0 & 0 \\
\hline $\begin{array}{l}\text { d) Outros gastos de gestão } \\
\text { corrente }\end{array}$ & $(3.215)$ & (2.993) & (2.993) & $(2.844)$ & $(2.844)$ & (2.729) & $(2.784)$ \\
\hline B. Gastos gerados por navios & (877) & & $(2.700)$ & $(2.765)$ & $(2.765)$ & $(2.899)$ & $(2.957)$ \\
\hline C. Repasses a Portos de Estado & $(3.890)$ & $(3.942)$ & 0 & 0 & 0 & 0 & 0 \\
\hline $\begin{array}{l}\text { D. Fundo de compensação } \\
\text { interportuário }\end{array}$ & $(2.353)$ & $(4.119)$ & $(3.824)$ & $(4.500)$ & $(4.500)$ & $(6.451)$ & (7.099) \\
\hline 8. Depreciações e amortizações & $(46.170)$ & $(44.500)$ & $(44.500)$ & $(53.050)$ & $(43.050)$ & $(51.550)$ & $(51.400)$ \\
\hline $\begin{array}{l}\text { 9. Imputação de subvenções de } \\
\text { imobilizado }\end{array}$ & 2.731 & 2.774 & 2.774 & 4.624 & 4.624 & 4.624 & 4.624 \\
\hline 10. Excesso de provisões & 0 & 0 & & & & & \\
\hline $\begin{array}{l}\text { 11. Deterioração e alienação de } \\
\text { imobilizado }\end{array}$ & (188) & 0 & 0 & 0 & 0 & 10.550 & 0 \\
\hline a) Deterioração e perdas & 29 & 0 & & & & & \\
\hline $\begin{array}{l}\text { b) Resultados de alienações e } \\
\text { outros }\end{array}$ & $(217)$ & 0 & & & & 10.550 & \\
\hline
\end{tabular}

Fonte: Autoridade Portuária de Valência (2011).

Nota: Os valores entre parênteses são gastos e deduzidos das receitas. 
Os novos investimentos são pautados em estudos de viabilidade econômico-financeira, o que melhora os processos de seleção, aliada à elaboração plurianual, que permite verificar os efeitos desses investimentos em períodos maiores. O orçamento de investimentos deve ser acompanhado dos estudos de rentabilidade e dos relatórios de impacto ambiental do projeto.

Na avaliação dos investimentos, são aplicados os principais métodos de avaliação: payback, taxa interna de retorno, valor presente líquido e opções reais, além do Custo Médio Ponderado de Capital (WACC) para a definição da taxa mínima de retorno e da análise de cenários, sensibilidade, simulação e árvore de decisão para verificar o risco do investimento (Giner et al., 2012).

Os investimentos são examinados e revisados previamente pela Comissão de Investimentos antes de incorporar-se ao plano orçamentário. Isso porque esses novos investimentos podem afetar as demais peças orçamentárias, como o fluxo de caixa, receitas, produção, serviços de financiamento etc.

O orçamento é acompanhado de uma análise de indicadores econômico-financeiros, visando avaliar a eficiência e a eficácia, baseada nos objetivos estratégicos do porto, conforme ilustrado na tabela 2. Esses indicadores também fazem parte do sistema de mensuração e avaliação de desempenho estratégico, implementado na Autoridade Portuária de Valência por meio da ferramenta Cuadro de Mando Integral (também conhecida como Balanced Scorecard).

Tabela 2

Síntese dos principais indicadores de gestão orçamentária

\begin{tabular}{|lccccccc|}
\hline INDICADORES DE GESTÃO & 2009 & 2010 & 2011 & 2012 & 2013 & 2014 & 2015 \\
\hline Receita líquida / Valor médio (em R\$) & 256,2 & 186 & 283,5 & 307 & 332 & 358,4 & 370,4 \\
Resultado operacional / Receita líquida (× 100) & 19,5 & 31 & 20,4 & 22,5 & 26,1 & 38,3 & 32,9 \\
Lucro do exercício / Valor médio (em R\$) & 50,6 & 57 & 30,3 & 24,2 & 27,3 & 75,3 & 61,2 \\
Fluxo de caixa / Saldo do endividamento L.P. (× 100) & 6,4 & 0 & 8,9 & 10 & 11 & 12,3 & 12,4 \\
Gastos / Receitas (× 100) & 94,5 & 81 & 80,7 & 78,8 & 74,6 & 69,7 & 68 \\
\hline
\end{tabular}

Fonte: Autoridade Portuária de Valência (2011).

O objetivo fundamental desse plano é auxiliar no estabelecimento de ações e decisões prévias do porto. Ele visa não restringir as atividades do porto, e sim definir o que se quer e proporcionar os meios necessários para alcançar seus objetivos, transformando as ideias em ações e planos operacionais. Esse modelo permite que o porto tenha flexibilidade na aplicação dos recursos, já que apenas o aumento de pessoal e novos investimentos precisam de aprovação de órgão público superior; os demais gastos podem ser realizados de acordo com as necessidades.

Nessa nova forma de elaboração, o orçamento se converte em uma oportunidade de revisar o negócio do porto. Isso produz uma mudança cultural, na qual o orçamento deixa de 
ser um fim em si mesmo, obrigatório por leis e normas do setor público, para transformar-se em um instrumento de gestão dentro do planejamento estratégico. Ou seja, deixa de ser um instrumento de distribuição de recursos para se converter em uma ferramenta de planejamento e controle, auxiliando os gestores nas ações e tomada de decisão.

No controle orçamentário, um ponto importante é o papel que o monitoramento tem no sistema de gestão da organização. Pesquisas em empresas mostram que o orçamento é o principal indicador de desempenho e um dos poucos indicadores-chave de desempenho em empresas na Turquia (Uyar e Bilgin, 2011) e no Reino Unido (Jones, 2008a).

\subsubsection{Principais mudanças, dificuldades e benefícios}

Pode-se dizer que a mudança no sistema de orçamento está ligada à evolução do SPTE, o que permitiu modernizar o planejamento estratégico e, com essa mundança, os processos e ferramentas de planejamento econômico e financeiro de curto prazo.

As mudanças ocorridas no planejamento do orçamento ocorreram em diferentes pontos, conforme quadro 3. Primeiramente, pode-se enumerar a relativa à integração entre as medidas de desempenho e o orçamento, e aqui cabe destacar também as decorrentes da melhoria do planejamento com implementação do Balanced Scorecard no porto, onde são desenvolvidas as metas que possibilitam a integração entre o planejamento estratégico e operacional. Anteriormente, como o planejamento estratégico não era estruturado e implementado, a sua elaboração ocorria sem o alinhamento com as medidas de desempenho do porto.

Uma das mudanças no processo de elaboração do orçamento diz respeito às decisões, que agora são tomadas pelas pessoas diretamente envolvidas nas atividades do porto, o que pode ser classificado como uma forma combinada de preparação, porque inclui um manual com diretrizes, objetivos e metas a serem atingidos. Com as alterações realizadas, a previsão financeira torna-se apenas reflexo do planejamento operacional, o que permite a flexibilização do processo orçamentário.

Nessa sistemática, o orçamento se transforma em uma ferramenta de gestão econômico-financeira que contribui para os centros de responsabilidade, auxiliando a melhorar seu desempenho e atingir os resultados esperados, ao mesmo tempo que se torna um compromisso da Autoridade Portuária perante o SPTE. O quadro 3 ilustra as principais mudanças ocorridas no processo orçamentário a partir de 2004 na Autoridade Portuária de Valência.

Quadro 3

Síntese das principais mudanças ocorridas no processo orçamentário

\begin{tabular}{|c|c|c|}
\hline Características & Antes de 2004 & Depois de 2004 \\
\hline Manual de orçamento & Não & Sim \\
\hline Forma de elaboração & Top-down & Combinação \\
\hline Período de elaboração & Anual & Plurianual (cinco anos) \\
\hline
\end{tabular}




\begin{tabular}{|c|c|c|}
\hline Características & Antes de 2004 & Depois de 2004 \\
\hline Objetivos do orçamento & $\begin{array}{l}\text { Controlar previamente as } \\
\text { receitas e os custos }\end{array}$ & $\begin{array}{l}\text { Previsões de futuro (com dados financeiros, físicos e de } \\
\text { resultado) } \\
\text { Maximizar os resultados } \\
\text { Planificar, controlar e valorar os resultados } \\
\text { Criar incentivos e recompensas }\end{array}$ \\
\hline Informações utilizadas & Números de anos anteriores & $\begin{array}{l}\text { Tráfico do porto } \\
\text { Medidas de desempenho (planejamento estratégico e SPTE) } \\
\text { Projetos de investimento } \\
\text { Objetivos de rentabilidade } \\
\text { Análises de mercado } \\
\text { Indicadores econômicos nacionais, regionais e locais }\end{array}$ \\
\hline Critérios de avaliação & Com anos anteriores & $\begin{array}{l}\text { Com anos anteriores } \\
\text { Benchmarking com outros portos espanhóis e de outros países } \\
\text { Com as metas do planejamento estratégico }\end{array}$ \\
\hline $\begin{array}{l}\text { Finalidade da análise das } \\
\text { variações }\end{array}$ & Controlar receitas e custos & $\begin{array}{l}\text { Avaliar o desempenho de setor específico do porto } \\
\text { Controlar receitas e gastos } \\
\text { Reconhecimento a tempo de um problema } \\
\text { Feedback }\end{array}$ \\
\hline
\end{tabular}

Fonte: Elaborado pelos autores.

As principais mudanças implementadas no porto estão na direção daquelas apontadas na literatura por Umapathy (1987) e King, Clarkson e Wallace (2010), adotadas por empresas de sucesso. São elas: a geração de compromisso, o alinhamento entre os níveis da organização, a adoção de procedimentos detalhados e abrangentes na elaboração, além da análise das variações e tomada de ações corretivas.

Estre as principais mudanças incorporadas a partir de 2004 no processo orçamentário, pode-se destacar a integração dos objetivos estratégicos decorrentes do Plano Estratégico e a participação no processo de desenvolvimento das várias áreas e departamentos que atuam ativamente no processo de orçamentação, o que inclui o planejamento estratégico, o controle e o orçamento. A nova abordagem incorpora o orçamento à visão estratégica do Planejamento Estratégico, na implementação dos objetivos e das iniciativas estratégicas identificadas como prioritárias, para alcançar as metas estabelecidas no Plano Estratégico.

O processo de mudança apresentou algumas dificuldades, isso porque era necessário promover uma transformação cultural na organização, novos conhecimentos em abordagens estratégicas, o que exigia uma reestruturação dos departamentos e liderança forte associada às três áreas principais: estratégico, negócio e suporte. Esse processo levou um tempo para ser formado e exigiu persistência dos diretores do porto, o que está permitindo a implementação de um processo de transformação e melhoria contínua em todas as áreas e/ou departamentos da Autoridade Portuária. Ele foi reforçado com a implementação, desde 2004, do Balanced Scorecard (BSC), que permitiu comunicar a estratégia a todos os funcionários da Autoridade Portuária, com atribuição de responsabilidade a cada um. 
Entre os principais benefícios da aplicação desse plano, pode-se destacar que o novo sistema permitiu comunicar a estratégia a todos os funcionários, com atribuição de responsabilidade aos departamentos, que monitoram o orçamento de acordo com as linhas e as metas definidas no Plano Estratégico da Autoridade Portuária.

\section{Discussões e conclusões}

Esse novo processo orçamentário consolidado permite observar os valores globais do conjunto de portos e verificar sua evolução em relação a exercícios anteriores, bem como sua tendência futura. Com os resultados, é possível analisar tanto a situação econômico-financeira do porto específico quanto a do sistema portuário em sua totalidade, além da possibilidade de serem realizados estudos de benchmarking com portos de outros países.

Essa forma de elaboração do orçamento permite atender as normas do setor público, além de ser um poderoso instrumento de gestão das atividades desenvolvidas no porto. Com a eficiência e o desempenho baseados em cultura empresarial de resultados. Esse novo processo de elaboração do orçamento, tanto no sentido vertical, com a integração com medidas de desempenho do Balanced Scorecard, quanto no horizontal, com detalhamento e aproximação das dotações orçamentárias com os responsáveis, minimiza os problemas advindos de influências das estratégias partidárias, de política ideológica e de cobertura negativa da mídia, muito comuns em organizações dessa natureza (Grizzle, 1987; Joyce, 2008).

As organizações, de uma forma geral, precisam mudar seus processos orçamentários baseados no comando e controle (Libby e Lindsay, 2010), os quais, além de ineficientes, são verdadeiros elefantes brancos e com grande volatilidade (Janus, 2009). Nessa sistemática, quando ocorrem períodos de crise, aplicam-se medidas draconianas, com cortes lineares e demissões a curto prazo, além de ações que levam à diminuição do retorno no futuro (Perel, 2005).

Visando preencher essas lacunas e deficiências (Fairholm e Card, 2009), as reformas nos orçamentos, com base no desempenho, representam um grande desafio para os governos, especialmente nos países em desenvolvimento (Andrews, 2006). Segundo Tuegen e colaboradores (2008), as instituições públicas precisam preparar seus sistemas orçamentários de acordo com o mercado e focando o desempenho. A integração das medidas de desempenho com dotações é fundamental para o sucesso do orçamento (Poister e Mcgowan, 1984; Cope, 1987; Grizzle, 1986, 1987; Schick, 1990; Poister e Streib, 1989, 1999, 2005; Berman e Wang, 2000; Melkers e Willoughby, 2005; Hatry, 2006; Ho, 2011).

Talvez esse modelo possa ser uma excelente forma de superar as deficiências do sistema de administração pública brasileiro, principalmente dos portos. Isso porque, historicamente, o desenvolvimento dos sistemas de transportes não acompanhou as necessidades de infraestrutura para apoiar os investimentos produtivos no Brasil (Serra, Martins e Bronzo, 2009; Goulart Filho, 2007).

Isso corrobora Pizzoloto, Scarvarda e Paiva (2010), ao relatarem que, para enfrentar os desafios, os portos devem: (i) implantar planejamento estratégico, (ii) ter conhecimento de seu mercado de atuação, (iii) identificar os níveis de serviços exigidos por seus clientes, e 
(iv) identificar as oportunidades de negócios que possam alavancar suas movimentações de cargas, assim como o adequado conhecimento das vantagens relativas de seus concorrentes diretos, de forma a antecipar ações e garantir a expansão da movimentação portuária.

Pelas semelhanças no modelo de administração dos portos brasileiros e espanhóis, esse sistema representa uma oportunidade para os portos nacionais melhorarem seus processos de gestão, principalmente os relacionados ao orçamento. Pode também ser uma referência para a administração pública do Brasil, de uma forma geral, visando à melhoria de seus processos orçamentários.

O orçamento pode contribuir diretamente para a melhoria da aplicação dos recursos, aumentando a eficiência na execução e melhorando o controle pelos diferentes órgãos públicos, além da sociedade. Isso porque, com as melhorias apresentadas neste estudo, é possível avaliar não somente os gastos, mas também o desempenho esperado. Além de tornar-se um poderoso instrumento para evitar os gastos desordenados e sem critérios.

Contudo, a partir dos aspectos teóricos, observa-se que podem ser exploradas outras práticas orçamentárias no porto para apoiar as decisões gerenciais, entre as quais destacamse: (i) designar comitê de orçamento e estabelecer responsabilidades profissionais relacionadas a planejamento e controle orçamentário; (ii) desenvolver sistemas formais e sistemáticos de revisão mensal, trimestral ou semestral; (iii) explorar tipos diferentes de orçamentos, tais como orçamento base zero e beyond budgeting; e (iv) verificar a possibilidade de utilizar o orçamento para introduzir novos produtos e serviços.

\section{Referências}

ABDEL-KADER, Magdy; LUTHER, Robert. Management accounting practices in the British food and drinks industry. British Food Journal, Newport, v. 108, n. 5, p. 336-357, 2006.

AGÊNCIA NACIONAL DE TRANSPORTES AQUAVIÁRIOS. 2010. Disponível em: <www.antaq.gov. br>. Acesso em: 21 out. 2011.

ÁLVAREZ-DARDET ESPEJO, María C.; GUTIÉRREZ HIDALGO, Fernando. Contabilidad de gestión. Madri: Pirámide, 2010.

ANDREWS, Matthew. Beyond 'best practice' and 'basics first' in adopting performance budgeting reform. Public Administration and Development, Washington, v. 26, n. 2, p. 147-161, 2006.

ASOCIACIÓN ESPAÑOLA DE CONTABILIDAD Y ADMINISTRACIÓN DE EMPRESAS. La contabilidad de gestión en el Sistema Portuario Español. Documento n. 31. Madri: AECA, 2006.

AUTORIDAD PORTUARIA DE VALENCIA. Plan Estratégico 2015. Valência: APV, 2011.

BENCINI, Fabrizio et al. Come si prepara il budget: finalità, implicazioni e metodologie di construzione. Milão: Grupo24ora, 2009. 
BERMAN, Evan; WANG, XiaoHu. Performance Measurement in U.S. Counties: capacity for reform. Public Administration Review, Indiana, v. 65, n. 5, p. 409-220, 2000.

BISHOP, John. Beyond budgeting in practice. Chartered Accountants Journal, Auckland, p. 9-25, Dec. 2004.

BLUMENTRITT, Tim. Integrating strategic management and budgeting. Journal of Business Strategy, London, v. 27, n. 6, p. 73-79, 2006.

BROOKS, Mary R. The governance structure of ports. Review of Network Economics, v. 3, n. 2, p. 168-183, 2004.

CASTRO, Jessica K. et al. Prácticas presupuestarias aplicadas a las empresas hoteleras de Brasil: un estudio en la ciudad de Florianópolis. Revista Estudios y Perspectivas en Turismo, Buenos Aires, v. 21, n. 4, p. 904-924, 2012.

CLASSEN, Chester E. Development of the performance budget structure in the Department of the Army. Tese (doutorado) - Maxwell Graduate School of Citizenship and Public Affairs, Syracuse University, Jesse, 1971.

COPE, Glen H. Local government budgeting and productivity: friends or foes? Public Productivity Review, v. 10, n. 3, p. 45-57, 1987.

DE WAAL, André A. Is your organization ready for beyond budgeting? Measuring Business Excellence, v. 9, n. 2, p. 56-67, 2005.

DERFUSS, Klaus. The relationship of budgetary participation and reliance on accounting performance measures with individual-level consequent variables: a meta-analysis. European Accounting Review, v. 18, n. 2, p. 203-239, 2009.

FAIRHOLM, Matthew R.; CARD, Michael. Perspectives of strategic thinking: from controlling chaos to embracing it. Journal of Management \& Organization, v. 15, n. 1, p. 17-30, 2009.

GINER, Arturo F. et al. Práticas de orçamento de capital: um estudo comparativo entre portos do Brasil e da Espanha. In: CONGRESO IBEROAMERICANO DE ADMINISTRACIÓN EMPRESARIAL Y CONTABILIDAD, VIII Y CONGRESO IBEROAMERICANO DE CONTABILIDAD DE GESTIÓN, VI, 2012, Lima. Anais... Lima: PUC, 2012. 1 CD-ROM.

GONZÁLEZ LAXE, Fernando. Posibilidades del sistema portuario de Galicia con el futuro ensanchamiento del canal de Panamá. Instituto Universitario Estudios Marítimos. Jornada Proyecto Atmos. Santiago de Compostela: Universidad de la Coruña, 2007. p. 1-62. Disponível em: <www.atmos-placa4s.info/atmos/recursos/documentos/atmos/publicos/proyecto/40577 _134200715758.pdf $>$.

GOULART FILHO, Alcides. Melhoramentos, reaparelhamentos e modernização dos portos brasileiros: a longa e constante espera. Economia e Sociedade, Campinas, v. 16, n. 3, p. 455-489. 2007.

GRAVES, Nigel; DOLLERY, Brian. Local government reform in South Africa: an analysis of financial management legislative compliance by municipalities. Public Administration and Development, v. 29, n. 5, p. 387-414, 2009. 
GRIZZLE, Gloria A. Does budget format really govern the actions of budgetmakers? Public Budgeting and Finance, v. 6, n. 1, p. 60-70, 1986.

GRIZZLE, Gloria A. Linking performance to funding decisions: what is the budgeter's roles? Public Productivity Review, v. 10, n. 3, p. 33-44, 1987.

HATRY, Harry P. Performance measurement: getting results. 2. ed. Washington, DC: Urban Institute, 2006.

HERVER, Trevor D.; MESERSMAN, Hilda; VAN DER VOORDE, Eddy. Cooperation and competition in international container transport: strategic for ports. Maritime Policy and Management, v. 28, n. 3, p. 293-305, 2001.

HO, Alfred T. K. PBB in american local governments: it's more than a management tool. Public Administration Review, v. 71, n. 3, p. 391-411, 2011.

HOPE, Jeremy; FRASER, Robin. Budgets: The hidden barrier to success in the information age. Accounting \& Business. v. 2, n. 3, p. 1-15, 1999.

HOPE, Jeremy; FRASER, Robin. Who needs budgets? Harvard Business Review, v. 81, n. 2, p. 108130, 2003.

HORNGREN, Charles T.; FOSTER, George; DATAR, Krikant M. Contabilidade de custos. 9. ed. Rio de Janeiro: LTC, 2000.

JANUS, Thorsten. Aid and the soft budget constraint. Review of Development Economics, v. 13, v. 2, p. 264-275, 2009.

JONES, Tracy A. Changes in hotel industry budgetary practice. International Journal of Contemporary Hospitality Management, v. 20, n. 4, p. 428-444, 2008b.

JONES, Tracy A. Improving hotel budgetary practice: a positive theory model. International Journal of Hospitality Management, v. 27, n. 4, p. 529-540, 2008a.

JONES, Tracy A. UK hotel operators use of budgetary procedures. International Journal of Contemporary Hospitality Management, v. 10, n. 3, p. 96-100, 1998.

JOYCE, Philip G. Does more (or even better) information lead to better budgeting? A new perspective. Journal of Policy Analysis and Management, v. 27, n. 4, p. 945-975, 2008.

KENSKI, Antonio C. Manual de orçamento na empresa. Rio de Janeiro: Apex, 1973.

KING, Robyn; CLARKSON, Peter M.; WALLACE, Sandra. Budgeting practices and performance in small healthcare businesses. Management Accounting Research, v. 21, n. 1, p. 40-55, 2010.

LEAHY, Tad. As 10 maiores armadilhas do orçamento. Revista HSM Management, n. 32, maio/jun. 2002.

LIBBY, Theresa; LINDSAY, Renee M. Beyond budgeting or better budgeting? Strategic Finance, v. 89, n. 2, p. 47-51, 2007. 
LIBBY, Theresa; LINDSAY, Renee M. Beyond budgeting or budgeting reconsidered? A survey of North-American budgeting practice. Management Accounting Research, v. 21, n. 1, p. 56-75, 2010.

LUNKES, Rogério J. Manual de orçamento. 2. ed. São Paulo: Atlas, 2007.

LUNKES, Rogério J.; RIPOLL, Vicente M.; ROSA, Fabricia S. Pesquisa sobre o orçamento na Espanha: um estudo bibliométrico das publicações em contabilidade. Revista Universo Contábil, v. 7, n. 3, p. 112-132, 2011.

MCVAY, Gloria J.; COOKE, David J. Beyond budgeting in an IDS: the Park Nicollet experience. Healthcare Financial Management, v. 60, n. 10, p. 100-110, Oct. 2006.

MELKERS, Julia; WILLOUGHBY, Katherine. Models of performance-measurement use in local governments: understanding budgeting, communication, and lasting effects. Public Administration Review, v. 65, n. 2, p. 180-190, 2005.

MOLL, Jodie; HOQUE, Zarirul. Budgeting for legitimacy: the case of an Australian university. Accounting Organizations and Society, v. 36, n. 2, p. 86-101, 2011.

MUÑIZ, Luís. Control presupuestario: planificación, elaboración y seguimiento del presupuesto. Barcelona: Profit, 2009.

NEELY, Andy; BOURNE, Mike; ADAMS, Chris. Better budgeting or beyond budgeting? Measuring Business Excellence, v. 7, n. 3, p. 22-28, 2003.

OAK, Seonghee; SCHMIDGALL, Raymond S. Have budgetary controls in the US club industry changed from the mid-1980s to the twenty-first century? International Journal of Contemporary Hospitality Management, v. 21, n. 4, p. 411-421, 2009.

ORGANISMO PÚBLICO PUERTOS DEL ESTADO. Disponível em: < http://www.puertos.es/>. Acesso em: 25 out. 2011.

OSTERGREN, Katarina; STENSAKER, Inger. Management control without budgets: a field study of 'beyond budgeting' in practice. European Accounting Review, v. 20, n. 1, p. 149-181, 2011.

PAVLATOS, Odysseas; PAGGIOS, Ioannis. Management accounting practices in the Greek hospitality industry. Managerial Auditing Journal, v. 24, n. 1, p. 81-98, 2009.

PEREL, Mel. You can innovate in hard times. Research-Technology Management, v. 48, n. 4, p. 1423, 2005.

PIZZOLOTO, Nélio D.; SCARVARDA, Luiz F.; PAIVA, Rodrigo. Zonas de influência portuárias — hinterlands: conceituação e metodologias para sua delimitação. Gestão\&Produção, v. 17, n. 3, p. 553-566, 2010.

PLAYER, Steve. Why some organizations go beyond budgeting. The Journal of Corporate Accounting and Finance, v. 14, n. 3, p. 3-9, Mar./Apr. 2003.

POISTER, Theodore H.; MCGOWAN, Robert P. The use of management tools in municipal government: a national survey. Public Administration Review, v. 44, n. 3, p. 215-230, 1984. 
POISTER, Theodore H.; STREIB, Gregory. Elements of strategic planning and management in municipal government: status after two decades. Public Administration Review, v. 65, n. 1, p. 45-56, 2005.

POISTER, Theodore H.; STREIB, Gregory. Management tools in municipal government: trends over the past decade. Public Administration Review, v. 49, n. 3, p. 240-480, 1989.

POISTER, Theodore H.; STREIB, Gregory. Performance measurement in municipal government: assessing the state of the practice. Public Administration Review, v. 59, n. 4, p. 325-350, 1999.

PRENDERGAST, Gerald; WEST, Douglas; SHI, Yi-Zheng. Advertising budgeting methods and processes in China. Journal of Advertising, v. 35, n. 3, p. 165-176, 2006.

PRIETO, Angel M.; ZOFIO, José L.; ALVAREZ, Immaculada. Economies of scale, density and scope in public provision of basic local infrastructure. Hacienda Pública Española, v. 190, n. 3, p. 59-93, 2009.

RAMADHAM, Sayel. Budgetary accounting and reporting practices in Bahraini governmental units: an empirical study. International Business Review, v. 18, n. 2, p. 168-183, 2009.

RANKIN, Frederick W.; SCHWARTZ, Steven T.; YOUNG, Richard A. The effect of honesty preferences and superior authority on budget proposals. The Accounting Review, v. 83, n. 4, p. 1083-1099, 2008.

RICKARDS, Robert C. Beyond budgeting: boon or boondoggle? Investment Management and Financial Innovations, v. 3, n. 2, p. 62-76, 2006.

RIPOLL, Vicente M.; REQUENA, Alfonso. Puntos débiles de la presupuestación y su impacto en la competitividad de la empresa. Revista Harvard-Deusto Finanzas y Contabilidad, n. 66, p. 42-49, 2005.

ROSA, Fabricia S.; ENSSLIN, Sandra R.; ENSSLIN, Leonardo. Evidenciação ambiental: processo estruturado de revisão de literatura sobre avaliação de desempenho da evidenciação ambiental. Sociedade, Contabilidade e Gestão, Rio de Janeiro, v. 4, p. 4-8, 2009.

SANVICENTE, Antonio Z.; SANTOS, Celso C. Orçamento na administração de empresas: planejamento e controle. São Paulo: Atlas, 2000.

SCHICK, Allen. Budgeting for results: recent developments in five industrialized countries. Public Administration Review, v. 50, n. 1, p. 26-34, 1990.

SCHMIDGALL, Raymond; BORCHGREVINK, Carl; ZAHL-BEGNUM, Odd. Operations budgeting practices of lodging firms, in the United States and Scandinavia. International Journal of Hospitality Management, v. 15, n. 2, p. 189-203, 1996. SCHMIDGALL, Raymond; DEFRANCO, Agnes. Budgeting and forecasting: current practice in the lodging industry. The Cornell Hotel and Restaurant Administration Quarterly, v. 39, n. 6, p. 45-51, 1998. 
SCHMIDGALL, Raymond; NINEMEIER, Jack. Budgeting in hotel chains: coordination and control. The Cornell Hotel and Restaurant Administration Quarterly, v. 28, n. 1, p. 79-84, 1987.

SCHMIDGALL, Raymond; NINEMEIER, Jack. Food-service budgeting: how the chains do it. The Cornell Hotel and Restaurant Administration Quarterly, v. 26, n. 4, p. 51-57, 1986.

SERRA, Laura T.; MARTINS, Ricardo S.; BRONZO, Marcelo. Public-private environment in the port operation decision-making process in Brazil: a case study. RBGN-Revista Brasileira de Gestão de Negócios, v. 11, n. 31, p. 183-199, 2009.

SIVABALAN, Prabhu et al. An exploratory study of operational reasons to budget. Accounting and Finance, v. 49, n. 4, p. 849-871, 2009.

STEED, Emmett; GU, Zheng. Hotel management company forecasting and budgeting practices: a survey-based analysis. International Journal of Contemporary Hospitality Management, v. 21, n. 6, p. 676-697, 2009.

SUBRAMANIAM, Nava; MCMANUS, Lisa; MIA, Lokman. Enhancing hotel manager's organizational commitment: an investigation of the impact of structure, need for achievement and participative budgeting. International Journal of Hospitality Management, v. 21, n. 4, p. 303-320, 2002.

TER BOGT, Henk J.; VAN HELDEN, G. Jan. The role of consultant-researchers in the design and implementation process of a programme budget in a local government organization. Management Accounting Research, v. 22, n. 1, p. 56-64, 2011.

TUEGEN, Kamil et al. Analysis of critical control points of alternative decisions on the choice of Performance Based Budgeting System: the analysis of the practices in Turkey's public institutions. Romanian Journal of Economic Forecasting, v. 9, n. 3, p. 80-99, 2008.

TUNG, Nguyen H. Orçamento empresarial e custo-padrão. 4. ed. São Paulo: Edições UniversidadeEmpresa, 1994.

UMAPATHY, Srinivasan. Current budgeting practices in U.S. industry. Nova York: Quorum Books, 1987.

UYAR, Ali. An evaluation of budgeting approaches: traditional budgeting, better budgeting, and beyond budgeting. Journal of Academic Studies, v. 11, n. 42, p. 113-130, 2009.

UYAR, Ali; BILGIN, Necdet. Budgeting practices in the Turkish hospitality industry: an exploratory survey in the Antalya region. International Journal of Hospitality Management, v. 30, n. 2, p. 398408, 2011. Disponível em: <www.sciencedirect.com/science/article/pii/S0278431910000939bbib0150>. Acesso em: 25 out. 2011.

WELSCH, Glenn A. Orçamento empresarial. 4. ed. São Paulo: Atlas, 1973.

WINATA, Lanita; MIA, Lokman. Information technology and the performance effect of managers' participation in budgeting: Evidence from the hotel industry. International Journal of Hospitality Management, v. 24, n. 1, p. 21-39, 2005. 
YUEN, Desmond. The impact of a budgetary design system: Direct and indirect model. Managerial Auditing Journal, v. 21, n. 2, p. 148-165, 2006.

ZDANOWICZ, José E. Orçamento Operacional. Porto Alegre: Sagra, 1989.

Rogério João Lunkes fez pós-doutorado em contabilidade e é professor da Universidade Federal de Santa Catarina (UFSC).E-mail: lunkes@cse.ufsc.br.

Vicente Ripoll-Feliu é doutor em economia e professor da Universidad de Valencia. E-mail: Vicente. Ripoll@uv.es.

Arturo Giner-Fillol é doutor em contabilidade e diretor da Autoridad Portuaria de Valencia. E-mail: aginer@valenciaport.com.

Fabricia Silva da Rosa fez pós-doutorado em contabilidade e é professora da Universidade de Blumenau (Furb). E-mail: fabriciasrosa@hotmail.com. 